\title{
Integration of time of use (TOU) tariff in net energy metering (NEM) scheme for electricity customers
}

\author{
Abdul Hafiz Razali, MD Pauzi Abdullah, Mohammad Yusri Hassan, Dalila Mat Said, Faridah Hussin \\ School of Electrical Engineering, Faculty of Engineering, Universiti Teknologi Malaysia, Malaysia
}

\begin{tabular}{l}
\hline Article Info \\
\hline Article historys: \\
Received Mar 3, 2019 \\
Revised May 6, 2019 \\
Accepted May 29, 2019 \\
\hline
\end{tabular}

\section{Keywords:}

Net energy metering

Residential consumer

Solar energy

Time of use

\begin{abstract}
The introduction of Net Energy Metering (NEM) scheme for electricity customers in Malaysia is seen as an improvement from the previous Feed-In Tariff (FIT). However, the new NEM scheme only benefited the large residential customers but not to medium and small residential customers. Due to electricity tariff blocks structure, the large customers can avoid paying expensive tariff and hence reducing their electricity bill. This is not the case for medium and small customers since they are already paying lower tariff blocks due to their lower electricity consumption. This issue will discourage most residential customers to install solar PV system in their home and affect the Malaysia's renewable energy target. This paper proposed a NEM scheme that integrates Time of Use (TOU) electricity tariff to the scheme. The proposed NEM-TOU scheme will be simulated, tested and compared to the new NEM scheme by using practical small, medium and large residential customers' data. The results show that the proposed TOU-NEM scheme able to overcome the weakness of the current scheme where all customers (large, medium and low) can benefited by installing solar PV system in their home.
\end{abstract}

Copyright (c) 2019 Institute of Advanced Engineering and Science. All rights reserved.

\section{Corresponding Author:}

Abdul Hafiz Razali,

School of Electrical Engineering, Faculty of Engineering

Universiti Teknologi Malaysia,

Sultan Ibrahim Chancellery Building, Jalan Iman, 81310 Skudai, Johor, Malaysia.

Email: ahafiz73@graduate.utm.my

\section{INTRODUCTION}

Malaysia can be considered as a potential country for generating high power from solar PV system since it consistently exposes to the sun throughout the year. The monthly solar irradiation is around 400-600 $\mathrm{MJ} / \mathrm{m} 2$ and higher during Northeast monsoon period [1]. Despite its high potential, the PV generation in Malaysia is only about $0.2 \%$ of the total power generation and the total installed PV capacity in 2014 is only $168 \mathrm{MW}$ [2], which is far from the national target of $1 \mathrm{GW}$ of solar power capacity by 2020 [3].

Realizing the potential of solar energy and importance of renewable energy (RE) in Malaysia, various renewable energy (RE) policies have been introduced to encourage the public including residential customers to install their own renewable energy system. It started with the launching of the Small Renewable Energy Power Program (SREP) on 11 May 2001. Under this program, small RE power generation plants allowed to sell the electricity to the grid. Then Suria 1000 project is introduced where the government provides subsidies for roof-top PV installation through a bidding system [4]. After that, feed-in tariff (FIT) scheme is introduced in 2011 for commercial and residential customers. The scheme is later replaced by net energy metering (NEM) scheme in 2016 and was improved in 2018. Compare to FIT, the new NEM scheme is seen to be less attractive since it only benefited the large customers (with high monthly kWh consumption). This paper proposed a new NEM scheme that utilizes time of use (TOU) pricing to overcome the problem. 


\section{NET ENERGY METERING SCHEME}

Net energy metering (NEM) has been introduced in the US since 1983. Different from FIT where all generated energy is sold to the grid, NEM allows consumers to generate, use and sell only the excess energy to the grid. The main objective of NEM is for self-consumption to reduce demand from the grid [5]. The policy requires the consumer to install a bidirectional meter. This net meter is able to show the users whether they are having excess or shortage of energy. If the meter rotates forward, it means that the users are taping energy from the grid and if it rotates backwards, it means the users are having excess of energy and hence import it from the grid. Any excess generation after billing period will be given credits, which is used to offset the consumers' electricity bill [6]. The maximum roll over credits period is 12 or 24 months. Depending on country's NEM policy, the remaining credits is either will be paid to consumer or will be set to zero. Indirectly, the policy has made the grid to act as a huge energy storage [7].

NEM is seen as a new policy that covers many weaknessesof the FIT policy. A well-designed NEM policy provides a simple, low cost, and easily administered way to deal with residential PV system. Since FIT requires a contract and two meters, it will be much more complex as compared to NEM. Inflation is another discouraging factors for FIT consumers since they will experience an incease in electricity tariff rate over time but fixed FIT rate paid to them [8]. In contrary, NEM acts like a perfect hedge against electricity price rise. Other than that, NEM policy able to reduce the power losses [9] by allowing the consumers to consume the generated energy first and only export the excess instead of exporting all generated energy.

However, NEM policy also have limitations. NEM takes longer years for return of investment as compared to FIT. Previous research [10] shows that NEM will takes 16.1 years compared to 11.5 years for FIT. Furthermore, some countries are implementing increasing-block rate electricity tariff, where the first block of kWh consumption is commonly charged at low rate. Thus NEM will not favour small consumers as they already paying low electricity bill even without PV system. Thus NEM does not guarantee profitable investment, especially for small consumers [9].

\subsection{Net energy metering in Malaysia}

NEM scheme was introduced in 2016 after looking at some improvements that can be made to the previous FIT scheme. In 2018, the government introduced the new NEM scheme that will start effectively on $1^{\text {st }}$ January 2019. In Malaysia, solar energy is eligible for all type of consumer. For residential, the allowable capacity is up to $12 \mathrm{~kW}$ for a single phase and $72 \mathrm{~kW}$ for a three phases system. While for commercial, industrial and agriculture is up to $1 \mathrm{MW}$. The excess generation will be credited into the next billing period at retail rate. The maximum roll over period is 24 months and any surplus after 24 months will be forfeit [11]. The details are summarized in Table 1.

Table 1. The new NEM structure in Malaysia

\begin{tabular}{|c|c|c|c|}
\hline Allowable Technology & Allowable Customer & Allowable Capacity & Net Excess Generation (NEG) \\
\hline \multirow[t]{2}{*}{$\begin{array}{l}\text { Solar } \\
\text { 1. } \text { Rooftop of building } \\
\text { 2. } \text { Garage, car park or } \\
\text { similar building }\end{array}$} & $\begin{array}{l}\text { Residential, } \\
\text { commercial, } \\
\text { industrial, }\end{array}$ & $\begin{array}{l}\text { Residential- } 12 \mathrm{~kW}_{\mathrm{p}}(\text { single } \\
\text { phase) } \\
72 \mathrm{~kW}_{\mathrm{p}}(3 \text { phase })\end{array}$ & $\begin{array}{l}\text { Any surplus will be credited in } \\
\text { the next billing period at retail } \\
\text { rate. }\end{array}$ \\
\hline & & $\begin{array}{l}\text { Commercial and industrial- } \\
1 \mathrm{MW} \text { p or } 75 \% \text { of maximum } \\
\text { demand or } 60 \% \text { of fuse } \\
\text { rating or } 60 \% \text { of current } \\
\text { transformer }\end{array}$ & $\begin{array}{l}\text { The max roll over period is } 24 \\
\text { months. Any excess credit after } \\
24 \text { months will be forfeit [11]. }\end{array}$ \\
\hline
\end{tabular}

\subsection{Electricity bill calculation using Malaysia's NEM scheme}

This subsection explains the electricity bill calculation using Malaysia's new NEM scheme. To compare the impact between large and small $\mathrm{kWh}$ consumers, 2 different residential consumers i.e. Home A and Home B are considered. Assume that both Home A and Home B have installed the same PV solar panel system with similar capacity of $2 \mathrm{kWp}$ that generate $10 \mathrm{kWh}$ of electrical energy per day. To simplify the calculation, it is assumed that the daily consumption of both customers fixed at $30 \mathrm{kWh}$ and $10 \mathrm{kWh}$ for Home A and B respectively. It is assumed the cost of $2 \mathrm{kWp}$ solar panel is RM 28000 and the lifetime of solar panel is 25 years. Consider simple payback, the cost of solar energy per month is RM 28000 , divided by 25 years times by 12 months. Therefore, the cost of solar energy for both Home A and B is RM 93.33 per month. Both consumers are required to pay the solar cost for each month for the next 25 years. In this case, the other cost such as maintenance, installation and other related cost are not considered. 
Both consumers will be compared in terms of electricity bill from i) existing billing (without solar PV system) and ii) with new NEM scheme (with PV system). The existing bill means that the standard residential billing structure without any solar pricing scheme. The mathematical formulation of the electricity bill calculation is given below. Key notations are summarized in Table 2.

Table 2. Notations

\begin{tabular}{ll}
\hline$P_{d, h}^{\text {consump }}$ & Energy consumption for a resident at specific hour, $\mathrm{h}$, and specific day, $\mathrm{d}$ \\
$P_{\text {total }}^{\text {Consump }}$ & Total energy consumption for a resident in a month \\
$P_{d, h}^{\text {generation }}$ & Energy generation from a resident at specific hour, $\mathrm{h}$, and specific day, $\mathrm{d}$ \\
$P_{\text {total }}^{\text {generation }}$ & Total energy generation for a resident jn a month \\
Price & Stariff \\
$P_{\text {total }}^{\text {net }}$ & Total net balance of energy consumption and generation \\
Electricity bill & Total electricity bill for a month \\
\hline
\end{tabular}

A. Mathematical formulation of existing electricity bill (without NEM)

$$
\begin{aligned}
& P_{\text {total }}^{\text {consump }}=\sum_{d=1}^{30} \sum_{h=1}^{24} P_{d, h}^{\text {consump }} \\
& \text { Electricity bill }=P_{\text {total }}^{\text {consump }} \times \text { Price }^{\text {tariff }}
\end{aligned}
$$

B. Mathematical formulation of existing electricity bill with NEM scheme

$$
\begin{aligned}
& P_{\text {total }}^{\text {generation }}=\sum_{d=1}^{30} \sum_{h=1}^{24} P_{d, h}^{\text {generation }} \\
& P_{\text {total }}^{\text {net }}=P_{\text {total }}^{\text {consump }}-P_{\text {total }}^{\text {generation }} \\
& \text { Electricity bill }=P_{\text {total }}^{\text {net }} \times \text { Price } \\
& \text { tariff }
\end{aligned}
$$

In this example, TNB electricity Tariff A (domestic tariff) is used. The tariff details as given in Table 3. Meanwhile, the NEM scheme is referred to Malaysia's new NEM scheme. The customer will consume the generated energy first and only the imported energy from the grid will be charged based on Tariff A - domestic tariff given in Table 3.

Table 3. Tariff a-domestic tariff

\begin{tabular}{cc}
\hline Tariff Category $(\mathrm{kWh})$ & Unit price $($ cent $/ \mathrm{kWh})$ \\
\hline $1-200$ & 21.80 \\
$201-300$ & 33.40 \\
$301-600$ & 51.60 \\
$601-900$ & 54.60 \\
$>900$ & 57.10 \\
\hline
\end{tabular}

The summary of the results are shown in Table 4. For Home A, the electricity bill for one month (assume 30 days) without PV system is RM395.60/month. The bill is greatly reduced into RM231.8/month with PV system. Even if the cost of PV is considered, the monthly cost for Home A is RM325.13/month which is still lower with the one without PV. This will be a good motivation for consumers to install solar PV system in their homes. However, this is not always true. Consider Home B, where it generated and consumed the same amount of $\mathrm{kWh}$ energy, which is $300 \mathrm{kWh}$ per month. The electricity bill for one month without PV system is RM77/month. Even though the electricity bill is RM0/month with PV system, the total cost is RM93.33/month when the cost of PV is considered. This shows that the monthly electricity cost for Home B will be increased when solar PV system is installed with NEM scheme. The results show that the implementation of the NEM scheme is only beneficial to large residential customer that consumed large amount of energy. No benefit for small customers.

Integration of time of use (TOU) tariff in net energy metering (NEM) scheme for......(Abdul Hafiz Razali) 
Table 4. Bill and cost comparison between home a and home $b$

\begin{tabular}{ccccccc}
\hline Consumer & $\begin{array}{c}\text { PV Generation } \\
\text { (kWh/Day) }\end{array}$ & $\begin{array}{c}\text { Total } \\
\text { Consumption } \\
\text { (kWh/Day) }\end{array}$ & $\begin{array}{c}\text { Electricity bill } \\
\text { without PV } \\
\text { (RM/Month) }\end{array}$ & $\begin{array}{c}\text { Electricity bill } \\
\text { with PV and } \\
\text { NEM scheme } \\
\text { (RM/Month) }\end{array}$ & $\begin{array}{c}\text { Total cost } \\
\text { without PV } \\
\text { (RM/Month) }\end{array}$ & $\begin{array}{c}\text { Total cost with } \\
\text { PV and NEM } \\
\text { scheme } \\
\text { (RM/Month) }\end{array}$ \\
\hline Home A & 10 & 30 & 395.60 & 231.8 & 395.60 & 325.13 \\
Home B & 10 & 10 & 77.00 & 0 & 77.00 & 93.33 \\
\hline
\end{tabular}

\section{TIME OF USE ELECTRICITY PRICING}

Time of use (TOU) is a structure of electricity tariff that charge electricity consumer based on the time of electricity use within a day. The consumption in different time will be charged at different rate based on the predetermined time division. The price will be low during off-peak, moderate during mid-peak and high during peak period. The main purpose of TOU is to encourage the consumer to shift the consumption from peak period to off-peak period thus the electricity demand can be stabilized [12]. Through TOU, electricity consumption of users will change duet o the change in electricity prices over time [13]. TOU implementation will benefit both users and the utility since the user can reduced the bills and the utility can reduced the peak demand and hence reduced the electricity cost.

Time of Use (TOU) electricity tariff basically gives a variety of prices based on electricity demand at certain times [14]. TOU consists of two or three period arrangements known as peak, mid-peak and off-peak period. The peak period is defined as the time where electricity demand is highest during the day and off-peak period is arranged according to lower electricity demand throughout the day. TOU typically yields higher price during peak period and lower price during off-peak period. Daily consumer demand usually has peaks resulting with high generation costs. This program mainly encourages consumers to be more energy efficient to reduce these peaks. Reducing peaks means to have an average generation cost that can help the electricity market in a long-term situation.

The measure would be load-shifting where it is defined by the act of shifting electricity consumption by consumers from peak hours to off peak hours. In Malaysia, Time of Use (TOU) electricity pricing is only applicable to commercial and industrial consumers [12-15], while residential consumers are still charged with fixed electricity prices regardless of their electricity consumption pattern for their electricity bills. This is caused by the difference between consumer's load profile patterns. Another TOU pricing scheme has to be implemented for residential consumer to assure the benefits of both consumers and utility is achieved [12]. The critical part of TOU system is to determine the most efficient price rate that gives consumers signals to change their consumption behaviour [16].

\section{PROPOSED TOU-NEM SCHEME}

This paper proposes that the existing NEM scheme is integrated with TOU pricing scheme to overcome the weakness of NEM scheme as presented in subsection 2.2. In the existing NEM scheme, the net consumption of a month is calculated at the end of the month in which the total electricity consumption in a month is substracted with the total electricity generation from solar PV system in a month, as given in equation (4). The electricity bill is calculated by multiplying the net consumption to the electricity tariff, as given in equation (5). For the proposed NEM-TOU method, the net consumption is calculated hourly, where the electricity bill is calculated hourly by multiplying the net consumption of a particular hour with the time of use (TOU) tariff for that hour. If the electricity consumption is higher than generation, the net consumption will be positive and the electricity bill will also be positive. It indicates the amount of electricity bill that the consumer need to pay for that hour. On the other hand, if the electricity consumption is lower than generation, the net consumption will be negative and the electricity bill will also be negative. The negative sign indicates that the utility need to pay the consumer for that hour. It can be mathematically presented as follows;

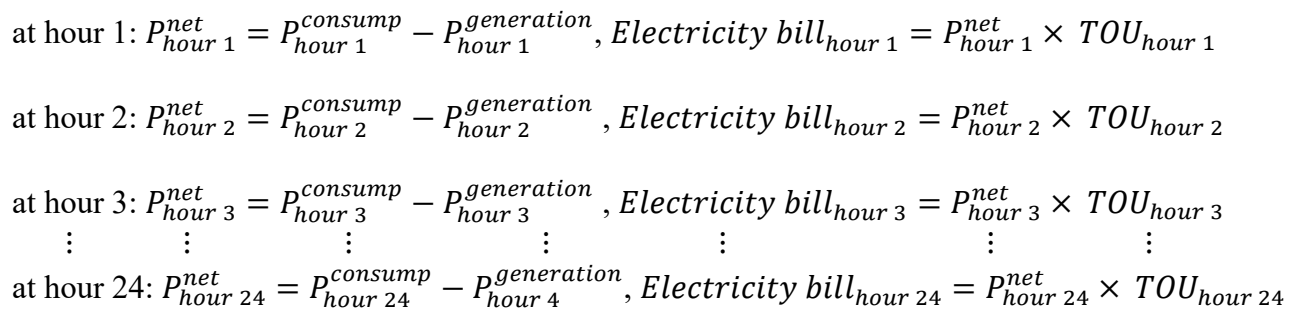

Electricity bill for one day $=$ Electricity bill $_{\text {hour } 1}+$ Electricity bill $_{\text {hour } 2}+\ldots$ Electricity $_{\text {bill }}$ hour 24 
Thus, the total electricity for one month can be formulated as follows;

Electricity bill in one month $=\sum_{d=1}^{30} \sum_{h=1}^{24}\left(P_{d, h}^{\text {consump }}-P_{d, h}^{\text {generation }}\right) \times T O U_{d, h}$

where, TOU $_{d, h}$ : Time-of-use tariff of day $d$ at hour $h$

\section{CASE STUDY}

This section will investigate the impact of the proposed NEM-TOU scheme of electricity bill on electricity customers. Three different residential customers i.e. Resident A, Resident B and Resident $\mathrm{C}$ will be used in the case study, each represents small, medium and large customers respectively. For comparison, the electricity bill from the existing NEM scheme and without PV system will be included.

\subsection{Case data}

The daily electricity consumption of resident A, B and C are given in Figure 1 [17]. To simplify the problem, it is assumed that the consumption pattern for the three residents is the same for 30 days (1 month). The pattern for each resident is modified in such a way that the total electricity consumption in one month for resident $\mathrm{A}, \mathrm{B}$ and $\mathrm{C}$ are $300 \mathrm{kWh}, 600 \mathrm{kWh}$ and $900 \mathrm{kWh}$ respectively. Assume that resident $\mathrm{A}, \mathrm{B}$ and $\mathrm{C}$ have installed the same solar PVpanel system with similar capacity of $2 \mathrm{kWp}$. The hourly electricity generation of the PV panel of the three residents is given in Figure 2 [18] and is assumed to be fixed for 30 days. The cost of $2 \mathrm{kWp}$ solar PV system is RM 93.33 per month, as previously calculated in subsection 2.2.

In this case, the TOU period will be divided into two parts, peak hours and off-peak hours. Peak hours will be started from $8 \mathrm{am}$ until $6 \mathrm{pm}$, while off-peak is started from $6 \mathrm{pm}$ until $6 \mathrm{am}$. The TOU price for each period is given in Table 5. It is assumed that TOU prices are fixed for 30 days.

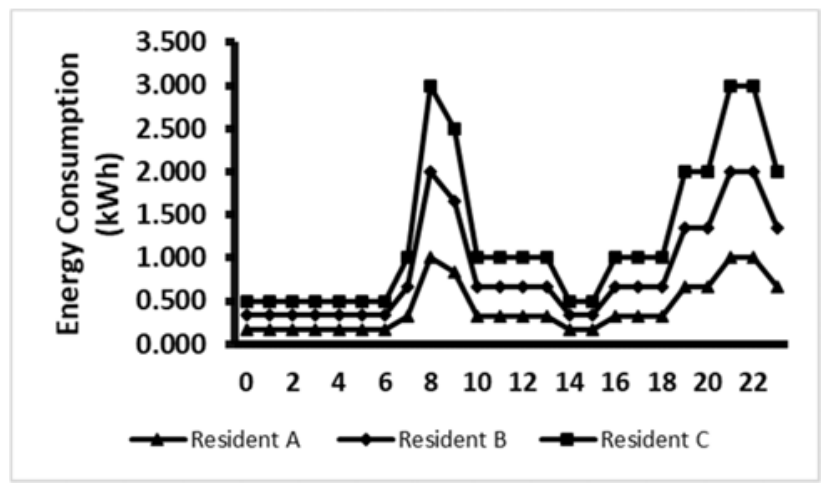

Figure 1. Load profile for resident A, B and C

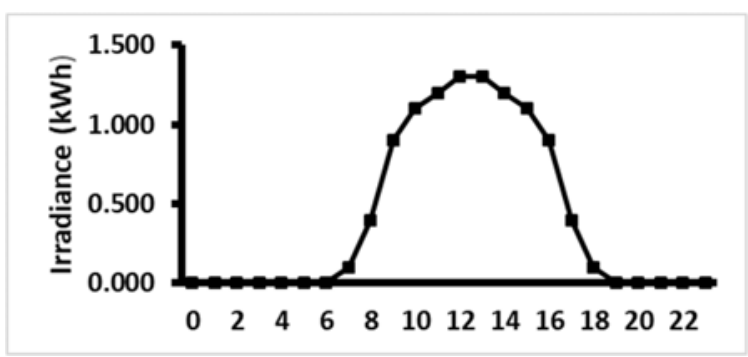

Figure 2. PV output for $2 \mathrm{~kW}_{\mathrm{p}}$ panel

Table 5 . TOU price during peak and off-peak period

\begin{tabular}{ccc}
\hline Period & Time & Charge \\
\hline Peak & $8 \mathrm{am}-6 \mathrm{pm}$ & 60 cents \\
Off-peak & $6 \mathrm{pm}-8 \mathrm{am}$ & 20 cents \\
\hline
\end{tabular}

Integration of time of use (TOU) tariff in net energy metering (NEM) scheme for......(Abdul Hafiz Razali) 


\subsection{Result and analysis}

Figure 3 shows the imported energy from the grid for 24 hours, which represents the net electricity consumption for each hour. The negative values indicate that the energy is exported to the grid, which means the electricity generation exceeds the consumption at that hour. Figure 4 illustrates the charge of electricity bill per hour for all type of residents. Charges at $8 \mathrm{am}$ were the highest due to high net electricity consumption and at peak times. While the charge at night $(6 \mathrm{pm}-11 \mathrm{pm})$ is at moderate rate, since the higher net electricity consumption but at off-peak period. Meanwhile, at $10 \mathrm{am}$ to $4 \mathrm{pm}$, the residents generate the profit due to negative net consumption (generates more than consumes) at peak hours. Finally, the charges at 12am until 6am is the lowest due to the low net consumption and at off-peak period.

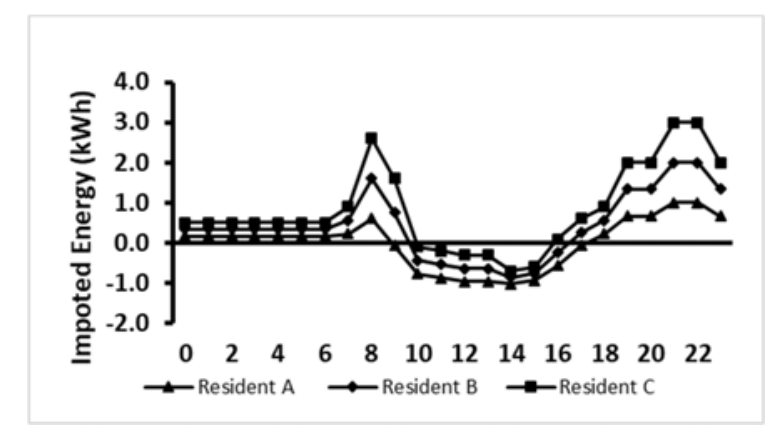

Figure 3. Imported energy from grid

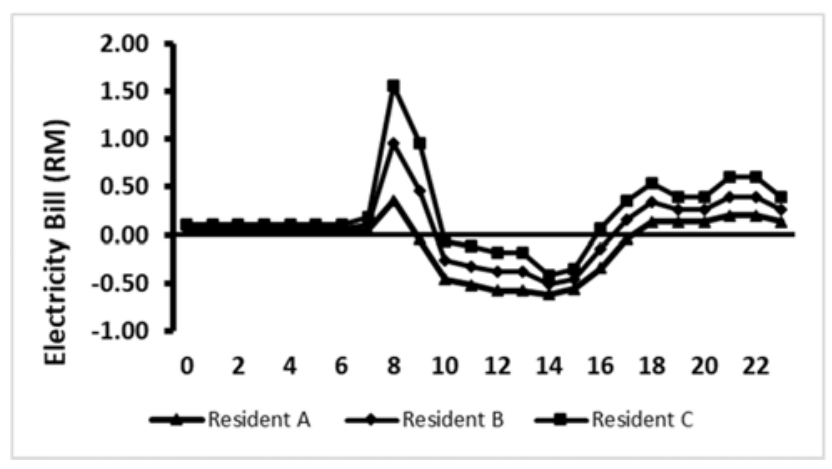

Figure 4. Electricity bill per hour

Based on Figure 4, the net charges need to be paid for all residents in a day are -RM 2.166, RM1.628 and RM 5.440 for Resident A, Resident B and Resident C respectively as shown in Table 6. Negative value indicates that the resident will get the credits from the utility. In a month, the values will increase to -RM 64.98, RM 48.84 and RM 163.20 for Resident A, Resident B and Resident C respectively. However, the values do not include solar cost which is RM 93.33 per month. After including the solar cost, the value will be RM 28.35, RM 42.17 and RM 56.53 for Resident A, Resident B and Resident C respectively.

Table 6. Electricity charge per day and per month

\begin{tabular}{cccc}
\hline Residents & Charge per day (RM) & Charge per month (RM) & $\begin{array}{c}\text { Charge per month (RM) } \\
\text { (include solar cost) }\end{array}$ \\
\hline A & -2.166 & -64.98 & 28.35 \\
B & 1.628 & 48.84 & 42.17 \\
C & 5.440 & 163.20 & 56.53 \\
\hline
\end{tabular}

Figure 5 shows the comparison of electricity bill for existing tariff (without PV), new NEM scheme and the proposed NEM-TOU scheme. The graph shows that resident A, which represent small consumers pay RM 77.00 under the existing bill. Under the new NEM scheme, resident A pays RM 93.33, which is higher 
than the existing bill (without PV). However, under the proposed NEM-TOU scheme, resident A only pays RM 28.35, which is lower than existing bill and new NEM scheme. Resident B pays RM 231.80 under the existing bill. Under new NEM and the proposed NEM-TOU scheme, resident B pays RM 170.33 and RM 142.53 respectively, which are lower than existing bill. Similar for resident C, the electricity bill under new NEM scheme and the proposed NEM-TOU pricing scheme are lower than existing bill.

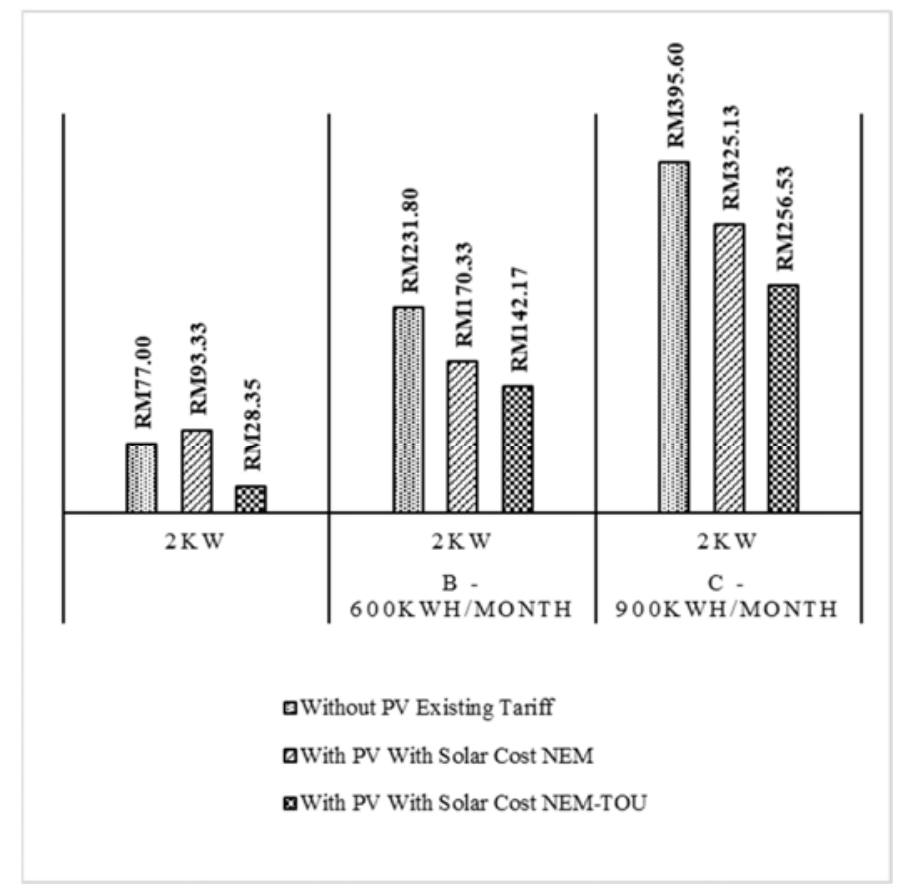

Figure 5. Electricity bill Comparison between the proposed NEM-TOU, NEM and existing bill

In term of percentage of saving if compared with existing tariff, under the new NEM scheme Resident A should pay $21.20 \%$ more than existing tariff, while under the TOU-NEM pricing the Resident A save $63.18 \%$ as shown in Figure 6. Meanwhile, Resident B save 26.52\% and 38.67\% under NEM and TOU-NEM scheme respectively. While, Resident $\mathrm{C}$ save $17.81 \%$ and $35.15 \%$ under new NEM and TOU-NEM scheme respectively. From the graph 5 and 6 , show that the NEM-TOU scheme provide better returns for small, medium and large residents.

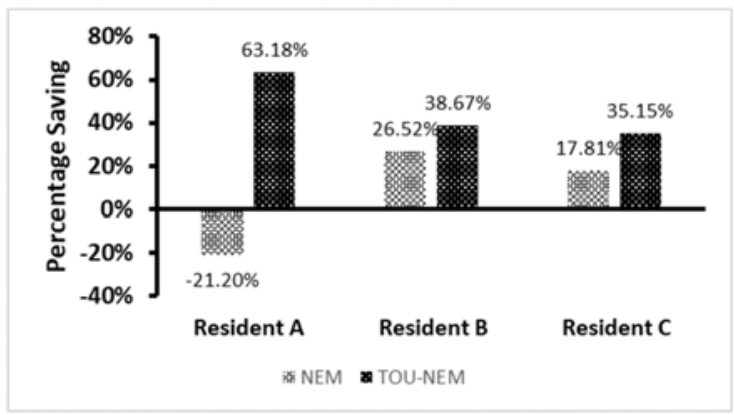

Figure 6. Percentage saving compared to existing bill

The results for resident A (small consumer) show that the proposed NEM-TOU method able to overcome the weakness of the new NEM method, in which it is disfavour for small consumers. The proposed method ensures all customers (from small to large) will benefited from solar PV system.

Integration of time of use (TOU) tariff in net energy metering (NEM) scheme for......(Abdul Hafiz Razali) 


\section{CONCLUSION}

This paper proposed NEM-TOU scheme for determining electricity bill of residential customers with solar PV system. It is based on hourly net consumption and hourly TOU price as compared to the monthly net consumption and fixed tariff that are used in the new NEM scheme. The case study results show that the proposed method able to offer a reduced electricity bill for all customers ranging from small, medium to large consumers. It overcome the weakness of the new NEM scheme, where small consumers do not benefit or having solar PV system installed in their home.

\section{REFERENCES}

[1] A. Nugroho, "The impact of solar chimney geometry for stack ventilation in Malaysia's single storey terraced house," Malaysia's Geography, vol. 2010, pp. 163-177, 2010.

[2] "TRENDS 2015 in Photovoltaic Applications," IEA-PVPS2015.

[3] "Renewables 2017 Global Status Report," REN212017.

[4] I. C. C. Fan, The Malaysian Feed-In Tariff, JURUTERA, 2012

[5] T. H. Oh, M. Hasanuzzaman, J. Selvaraj, S. C. Teo, and S. C. Chua., "Energy policy and alternative energy in Malaysia: Issues and challenges for sustainable growth - An update," Renewable and Sustainable Energy Reviews, vol. 81, pp. 3021-3031, 2018.

[6] A. Poullikkas, G. Kourtis, and I. Hadjipaschalis., "A review of net metering mechanism for electricity renewable energy sources," International Journal of Energy \& Environment, vol. 4, 2013.

[7] G. C. Christoforidis, I. P. Panapakidis, T. A. PapadopouIos, A. I. Chrysochos, G. K. Papagiannis, I. Koumparou, et al., (2014, Assessing policies for photovoltaic net-metering in Greece. IET Conference Proceedings, 24 (8)-24 (8). Available: http://digital-library.theiet.org/content/conferences/10.1049/cp.2014.1657

[8] B. Bakhtyar, K. Sopian, A. Zaharim, E. Salleh, and C. H. Lim., "Potentials and challenges in implementing feed-in tariff policy in Indonesia and the Philippines," Energy Policy, vol. 60, pp. 418-423, 2013.

[9] A. I. Nikolaidis and C. A. Charalambous, "Hidden financial implications of the net energy metering practice in an isolated power system: Critical review and policy insights," Renewable and Sustainable Energy Reviews, vol. 77, pp. 706-717, 2017.

[10] R. H. G. Tan and T. L. Chow, "A Comparative Study of Feed in Tariff and Net Metering for UCSI University North Wing Campus with 100 kW Solar Photovoltaic System," Energy Procedia, vol. 100, pp. 86-91, 2016.

[11] (5/10/17). Sustainable Energy Development Authority of Malaysia. Available: http://seda.gov.my/?omaneg=00010100000001010101000100001000000000000000000000\&s=5704

[12] N. S. Hussin, M. P. Abdullah, A. I. M. Ali, M. Y. Hassan, and F. Hussin., "Residential electricity time of use (ToU) pricing for Malaysia," in 2014 IEEE Conference on Energy Conversion (CENCON), 2014, pp. 429-433.

[13] M. H. Albadi and E. F. El-Saadany, "Demand Response in Electricity Markets: An Overview," in 2007 IEEE Power Engineering Society General Meeting, pp. 1-5, 2007.

[14] M. P. Abdullah, N. S. M. Nazar, M. Y. Hassan, and F. Hussin., "Optimizing time of use (ToU) electricity pricing in regulated market," Jurnal Teknologi, vol. 78, pp. 49-54, 2016.

[15] N. Nazar, M. Abdullah, M. Hassan, and F. Hussin., "Time-based electricity pricing for Demand Response implementation in monopolized electricity market," in Research and Development (SCOReD), 2012 IEEE Student Conference on, pp. 178-181, 2012.

[16] R. de Sá Ferreira, L. A. Barroso, P. R. Lino, M. M. Carvalho, and P. Valenzuela., "Time-of-use tariff design under uncertainty in price-elasticities of electricity demand: A stochastic optimization approach," IEEE Transactions on Smart Grid, vol. 4, pp. 2285-2295, 2013.

[17] T. Chin Ho and G. Chin Kim, "Impact of grid-connected residential PV systems on the malaysia low voltage distribution network," in 2013 IEEE 7th International Power Engineering and Optimization Conference (PEOCO), pp. 670-675, 2013.

[18] A. Ponniran, N. A. Mamat, and A. Joret., "Electricity profile study for domestic and commercial sectors," International Journal of Integrated Engineering, vol. 4, 2012.

Indo. J. Elec. Eng. \& Inf, Vol.7, No. 2, June 2019: 255 - 262 